\title{
La concentración en la industria manufacturera salvadoreña
}

\author{
Aquiles Montoya
}

\section{Resumen}

Este artículo analiza la problemática de la concentración y heterogeneidad estructural en la manufactura. Expone que la concentración y centralización del capital son tendencias normales del capitalismo y ambas se manifiestan en la concentración estadísticoestructural. Esta última en sí misma es resultado del crecimiento de las empresas, lo cual engrandece la economía pero también puede tener consecuencias negativas, como la formación de monopolios y oligopolios. Ahora bien, la concentración implica concentración de la propiedad y, por tanto, del ingreso, lo cual tiene repercusiones serias en términos sociales y de equidad.

\section{Introducción}

Este artículo se elaboró a partir de los VI Censos Económicos Nacionales, publicados en 1993 , que contienen información correspondiente a 1992. Se utilizaron los Tomos I y II, los cuales corresponden a la manufactura diversa con 5 y más ocupados, así como con 4 y menos ocupados, respeclivamente.

Con esta investigación se pretende mostrar, además de la problemática de la concentración y la heterogeneidad estructural en la manufactura, la necesidad de efectuar un estudio sobre la concen- tración a nivel de toda la economía en nuestro país, el cual, una vez finalizado, podría demostrar la hipótesis siguiente:

En El Salvador de los noventa se ha conformado un nuevo grupo oligárquico, cuya cara visible se presenta en el control que unas cuantas familias poseen sobre el sistema financiero nacional.

Ciertamente, si se habla de grupo oligárquico es porque esas familias, que controlan las finanzas, también controlan otros sectores importantes de la actividad económica nacional, como la industria, el comercio, el agro, el transporte, la construcción, 
etc. El importante control económico que ya poseían sobre esos otros sectores económicos fue lo que los posibilitó a acceder a la banca cuando ésta se privatizó, así como a otras instituciones financieras importantes.

El nuevo grupo oligárquico aún conserva la presencia de algunas antiguas familias, como los Dueñas, los Salaverría, los De Sola, los Llach, los Hill, etc., al cual se han incorporado nuevos apellidos: Poma, Cristiani, Quiróz, Simán, Salume, Bahaia, Yacir, etc.

Resulta interesante observar cómo las familias de origen árabe, conocidas como los "turcos" en nuestro medio - los mismos que durante muchos años estuvieron marginados de la élite económica y social del país-, aprovecharon los años de la guerra para acumular recursos financieros significativos y controlar actividades industriales importantes, además del comercio que ya poseían y que parecía ser su actividad natural o congénita. Esto les permitió convertirse en importantes sujetos dentro de la actividad económica nacional a tal punto que, cuando llegó la hora de medir sus fuerzas económicas - esto es, en el momento en que se distribuyó la banca - no hubo modo de dejarlos fuera de la rapiña, y como algunos comandaban el proceso, se sirvieron con la cuchara más grande.

Para dar una idea del nuevo grupo oligárquico que se ha venido conformando, se señala, a manera de ejemplo, que las familias que controlan los tres principales bancos también controlan las principales compañías de
... si se habla de grupo oligárquico es porque esas familias, que controlan las finanzas, también controlan otros sectores importantes de la actividad económica nacional... zos económicos que unen a las distintas familias que integran el grupo oligárquico, quizá, a lo sumo, se podrían presentar a aquellas familias que tienen intereses en dos o más sectores económicos, además de los que poseen en el sistema financiero nacional. Estas son:

\begin{tabular}{lll} 
Alvarez & Llach \\
Araujo Eserski & $\cdot$ & Llacha Hill \\
Baldocci Dueñas & $\cdot$ & Mathies \\
Bahaia & $\cdot$ & Mathies Regalado \\
Belismelis & $\cdot$ & Mathies Hill \\
Borgonovo Pohl & $\cdot$ & Murray Meza \\
Borja Nathan & $\cdot$ & Nasser \\
Call & $\cdot$ & Poma \\
Cohen & $\cdot$ & Palomo \\
Choussy & $\cdot$ & Quiróz \\
Cristiani & $\cdot$ & Ruiz Quiróz \\
De Sola & $\cdot$ & Safie \\
Dueñas & $\cdot$ & Salaverría \\
Dutriz & $\cdot$ & Salume \\
Eserski & $\cdot$ & Samayoa \\
García Prieto & $\cdot$ & Silhy \\
Handal & $\cdot$ & Simán \\
Hill & $\cdot$ & Sol \\
Hill Arguello & $\cdot$ & Tesak \\
Kriette & $\cdot$ & Vilanova \\
Lemus O’byrne & $\cdot$ & Zablah \\
\hline
\end{tabular}

El grupo oligárquico se subdivide en subgrupos que se han denominado: "argollas". Generalmente estos subgrupos son los que presentan diferencias económicas entre sí y cuando no hay manera de resolverlos de manera dialogada, pueden Ilegar, seguros, las más grandes

AFP, así como empresas dedicadas a los servicios de tarjetas de crédito, corredoras de bolsa, almacenes, producción y distribución de cerveza, de cemento, beneficios de caña de azúcar y de café, transportes aéreos, distribuidoras de automóviles, de bienes de consumo, etc.; y los bancos Agrícola Comercial, Cuscatlán y Salvadoreño poseen más del 50 por ciento de los activos financieros y más de la mitad del total de depósitos, con lo cual pueden controlar el crédito en nuestro país (ver Anexo número 1).

En este artículo, que se circunscribe al sector manufacturero, no será posible evidenciar los la- inclusive, al ámbito de los tribunales de justicia, dependiendo de cual sea el poder político que tenga uno u otro grupo en determinado momento.

No obstante $-y$ precisamente por la forma en que operan los poderes en estas sociedadessiempre se buscará contar con mayor influencia o control de los poderes públicos: ejecutivo, legislativo y judicial, para desarrollar las actividades económicas con cierta ventaja. Por esa razón, en los períodos previos a las elecciones se presentan ciertos movimientos y acciones de los sectores dominantes no muy claras ni comprensibles para la generalidad de las personas, que no estamos al 
tanto de sus luchas intestinas. Tal fue el caso de Finsepro-Insepro, o bien, estas declaraciones de un fundador de ARENA y ex miembro del COENA:

Al asumir Alfredo Cristiani la presidencia del COENA, es evidente que la derecha mercantilista se ha tomado el partido...

Estos individuos son los mismos que se repartieron los bancos en una privatización amañada en sus inicios; los que impiden el acceso de más líneas aéreas... los que quieren entregarle el manejo del aeropuerto a las líneas locales; los que quieren mantener en secreto los contratos de generación eléctrica y bloquear nuevos proyectos privados; los que se oponen sistemáticamente a la liberalización del comercio; los que no quieren una verdadera independencia del Banco Central de Reserva; los que se resisten a los cambios estructurales que no permitan las licitaciones amañadas; los que se oponen a la descentralización; los que pretenden que las leyes y estructuras deben estar al servicio de una nueva oligarquía económica'.

Lo anterior quizá pueda resultar de interés para los analistas políticos o para quienes tienen en alta estima a la democracia, ya que la concentración de tanto poder económico, indudablemente, incide de manela negativa en la democracia política; pero a la sociedad, como un todo, ¿qué más le da que existan $o$ no grupos o subgrupos oligárquicos? Parte de la explicación se encuentra en que tales entramados económicos limitan el libre juego de la oferta y la demanda, el cual se considera como un mecanismo fundamental para el buen funcionamiento del mercado. La no existencia de la libre competencia se traduce en competencia deslcal o en mayores coslos para los consumidores o usuarios de tal o cual servicio; además de otras posibilidades, no muy honorables, que se abren para tales poderosos grupos económi- cos, como la evasión de impuestos, el soborno, el lavado de dólares, etc.

Pero bien, de muy poca utilidad resulta despotricar contra esta o aquella acción de los grupos empresariales capitalistas, cuando es el sistema el que conduce inexorablemente a tales frutos o resultados $y$, en consecuencia, los empresarios, quienes objetivan acuerdos, compras o delitos, son tan sólo actores del drama capitalista y adoradores del gran dios capital, a cuyo servicio y voluntad se encuentran por más que actúen frente a nosotros, los simples mortales, con tanta soberbia e impunidad.

\section{Marco conceptual}

Entre las muchas tendencias que presenta el sistema capitalista existen aquellas que pueden considerarse como tendencias normales del sistema, entre ellas cabe destacar las tendencias a la concentración y centralización del capital. $Y$ es que el proceso de crecimiento de una empresa fundamentado en la reinversión de sus ganancias, que es lo que se tipifica como proceso de concentración de! capital, obviamente es un proceso que se corresponde con la normalidad capitalista. Este proceso -que tiene como resultado que el capitalista controle una mayor cantidad de empleados, así como una mayor canlidad de medios de producción y de productos, lo cual se conoce como concentración del capital- no puede ser más que normal dentro de la lógica del capitalismo.

Lo propio, lo normal del capitalismo es que las empresas crezcan; anormal sería que las empresas se mantuvieran estáticas a lo largo de los años. Para el caso de nuestro país, si La Constancia se mantuviera igual que hace 92 años, cuando se inició allá en Santa Ana en 1906, ello sería anormal y además imposible. puesto que de no haber crecido seguramente ya hubiese quebrado por efecto de la competencia de otra(s) fábrica(s), o bien, a causa de la importación

I. Mena Lagos, Alfredo, “;Basta ya!”, El Diario de Hoy, septiembre 22, 1997. 


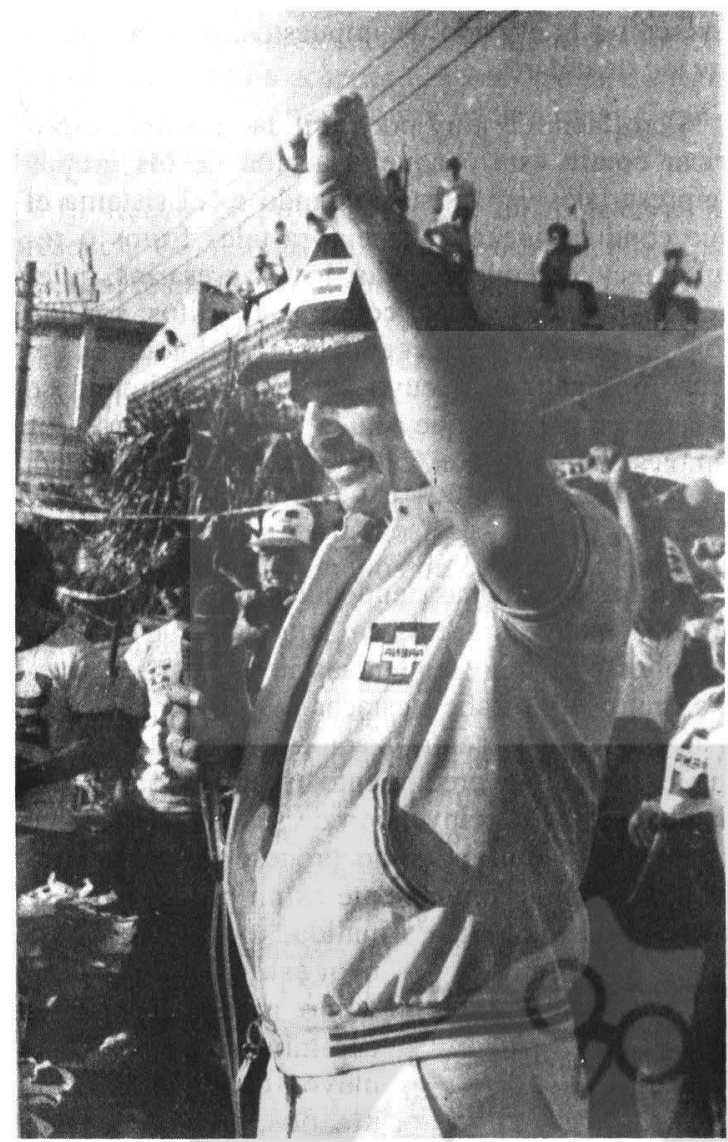

de otras cervezas. Lo mismo puede decirse respecto a TACA. Y el que se haya beneficiado de la guerra, como de la postguerra, del gobierno como de los hermanos lejanos, del futbol o de los artistas, etc. eso es cuestión aparte, ya que los mecanismos de concentración y centralización del capital, como los cristianos, cargan con el pecado original más todos los que logran acumular en su vida social y mundana.

El crecimiento de las empresas a veces no se logra mediante el proceso de reinversión de utilidades - como lo hubimos de presentar anteriormente; es un proceso que suele ser muy lento ya que depende del crecimiento de la economía como un todo-, sino que ocurte por absorción de otras empresas o por fusión con las mismas. A este proceso, para diferenciarlo del primero, se le denomina centralización del capital. Ejemplos de centralización del capital ocurren cuando la Daimler-
Benz, empresa alemana productora de vehículos de lujo, adquiere el control de la norteamericana Chrysler Corp, productora de vehículos familiares, - cuando "nuestra" TACA logra el control de Aviateca, Sahsa, Lanica y Lacsa.

Desde la lógica del capital, este proceso de centralización del capital, que posibilita un crecimiento acelerado, resulta también un proceso normal y tan legítimo como el anterior, aunque en el caso de la centralización del capital no sea tan legítimo como a simple vista parece, ya que se puede acudir a prácticas canivalescas cuando las empresas oponen alguna resistencia a ser absorbidas. También puede haber consecuencias negativas en materia laboral, ya que generalmente los procesos de centralización van acompañados de algunos despidos de trabajadores que resultan estar de más para las necesidades relativas del capital; o bien, pueden presentarse consecuencias socialmente negativas, como cuando se elevan los precios de las mercancías y servicios, o se suspende la producción de uno o varios artículos a causa de la centralización.

Pero ya sea que se trate de un proceso de concentración o de centralización del capital, el resultado en ambos casos es lo que se suele denominar como concentración estadístico-estructural. Esta puede indicar varios fenómenos, entre los cuales cabría mencionar el hecho de que una sola empresa controlara la producción nacional de un determinado producto, como sería el caso de $\mathrm{La}$ Constancia en el país; a este fenómeno también se le denomina monopolio y constituye el máximo de concentración que puede ocurrir en una determinada rama de la producción; o bien, que un pequeño número de empresas controlara un elevado porcentaje del valor agregado en una determinada rama industrial, tal sería el caso de la refinación de petróleo en el país, fenómeno al cual se le conoce también por oligopolio; o puede ser también que a un porcentaje muy bajo de capitalistas les pertenezca un elevado porcentaje de la propiedad de las empresas industriales, comerciales, agropecuarias, bancarias, etc. de un país. A este fenómeno, que termina por asumir contenidos políticos, se le conoce en distintos países de América Latina, y particularmente en El Salvador, como fenómeno oligárquico, pero obviamente se trata de una concentración estadístico-estructural. 
Pero más que teorizar sobre el tema ${ }^{2}$, interesa presentar alguna evidencia empírica al respecto aprovechando la reciente publicación de los Censos Económicos, los cuales muestran la información necesaria para estudiar el tema de la concentración.

\section{La concentración estadístico-estructural en la manufactura salvadoreña ${ }^{3}$}

El fenómeno de la concentración estadísticoestructural, para su mejor comprensión, se analizará en las empresas con 4 y más personas ocupadas, esto es, las empresas del sector formal o capitalista y lo hará primero según el Valor Bruto de la Producción (VBP), luego según las personas ocupadas $y$, finalmente, de acuerdo con las distintas ramas de actividad. Posteriormente se estudiará la concentración en el sector no capitalista, conocido como informal, esto es, en aquellas empresas con menos de 4 ocupados. Para finalizar, se presentará una visión de todo el sector industrial, esto es, del sector formal e informal.

\subsection{Industria manufacturera de 5 y más perso- nas ocupadas}

Para facilitar la comprensión del fenómeno en estudio, las distintas empresas manufactureras se clasificarán en pequeñas, medianas y grandes, según el monto del Valor Bruto de la Producción (VBP). Así se tiene que las empresas pequeñas son aquellas que tienen una producción bruta de hasta 1 millón de colones anuales; medianas, las que tengan una producción bruta de más de 1 millón hasta 50 millones de colones anuales, y grandes, aquellas de más de 50 millones. En rigor, éste es el sector capitalista de la industria manufacturera, al cual también se le denomina sector formal.

Al procesar la información suministrada por la Dirección General de Estadísticas y Censos para 1992, se obtuvieron los resultados siguientes (ver Cuadro 1):

\section{Cuadro 1}

Estructura de las empresas de la industria manufacturera con más de 4 personas ocupadas, según el Valor Bruto de la Producción (VBP), 1992

\begin{tabular}{|c|c|c|c|c|c|c|c|}
\hline \multirow[b]{2}{*}{$\begin{array}{l}\text { Valor Bruto } \\
\text { Producción }\end{array}$} & \multirow[b]{2}{*}{$\begin{array}{l}\text { No. de } \\
\text { Empresas }\end{array}$} & \multicolumn{2}{|c|}{ Ocupados } & \multicolumn{4}{|c|}{ Valor en miles de colones } \\
\hline & & Total & Remunerados & $\begin{array}{l}\text { Remunerac. } \\
\text { pagadas* }\end{array}$ & Activo fijo & Prod. bruta & $\begin{array}{l}\text { Valor } \\
\text { agregado }\end{array}$ \\
\hline Pequeñas & 946 & 8,244 & 6,848 & 87,708 & 126,644 & 325,941 & 166,208 \\
\hline Medianas & 556 & 45,764 & 44,887 & 936,497 & $1,525,137$ & $4,830,931$ & $2,350,780$ \\
\hline Grandes & 66 & 26,227 & 26,158 & $I, 123,554$ & $3,690,019$ & $14,097,977$ & $5,404,489$ \\
\hline Total & 1,568 & 80,235 & 77,893 & $2,147,759$ & $5,637,800$ & $19,254,849$ & $7,921,477$ \\
\hline
\end{tabular}

* Incluye: pagos al ISSS y otras remuneraciones.

Fuente: DIGESTYC, Censos Económicos, 1992.

El cuadro anterior arroja información interesante, como el que la mayoría de empresas en el subsector son pequeñas; que las medianas ocupan a más personas, pero que las grandes son las que pagan una mayor cantidad de remuneraciones, las que tienen mayores activos fijos, una mayor producción y que generan la mayor cantidad de valor agregado.

2. Puede obtener mayor información sobre este tema en Montoya, Aquiles, Economía Crítica, Cap. 8, San SalvaJor: Editores Crítico, 1998.

3. La información cuantificada que se presenta ha sido procesada a partir de los Censos Económicos de 1992. publicados por la Dirección General de Estadisticas y Censos (DIGESTYC). 
El subsector manufacturero con más de 4 personas ocupadas por empresa, suma un total de 1,568 empresas, las cuales, según el valor bruto de la producción, se pueden clasificar en: 946 pequeñas, 556 medianas y tan sólo 66 grandes. En conjunto, las 1,568 empresas dan ocupación a 80,235 personas, de las cuales 2,342 son no asalariadas -que pueden ser patronos y familiares no remunerados - y representan apenas un 2.9 por ciento del total de ocupados. Al margen de cualquier consideración, cs preciso señalar que el proletariado manufacturero en El Salvador es una fuerza cuantitativamente poco significativa.

Por otra parte, al observar el Cuadro 2 se encuentra una primera aproximación a la problemática de la concentración, como lo es el que tan sólo el 4.21 por ciento de las empresas controla el 53.3 por ciento de las remuneraciones, el 69.2 por ciento de los activos fijos, el 73.2 por ciento de la producción bruta y 68.2 por ciento del valor agregado.

\section{Cuadro 2}

Estructura porcentual de las empresas de la industria manufacturera con más de $\mathbf{4}$ personas ocupadas, según el Valor Bruto de la Producción (VBP), 1992

\begin{tabular}{lllrrrrr}
\hline VBP & $\begin{array}{l}\text { No } \\
\text { emipresas (\%) }\end{array}$ & $\begin{array}{l}\text { Total } \\
\text { ocupados (\%) }\end{array}$ & \multicolumn{1}{l}{$\begin{array}{l}\text { Remunerados } \\
(\%)\end{array}$} & $\begin{array}{l}\text { Remun. } \\
\text { pagadas (\%) }\end{array}$ & $\begin{array}{l}\text { Activo } \\
\text { fijo (\%) }\end{array}$ & $\begin{array}{l}\text { Prod. } \\
\text { bruta (\%) }\end{array}$ & $\begin{array}{c}\text { Valor } \\
\text { agregado (\%) }\end{array}$ \\
\hline Pequeñas & 60.33 & 10.27 & 8.79 & 4.08 & 2.41 & 1.69 & 2.10 \\
Medianas & 35.46 & 57.04 & 57.62 & 43.60 & 28.57 & 25.09 & 29.68 \\
Grandes & 4.21 & 32.69 & 33.58 & 53.31 & 69.23 & 73.22 & 68.23 \\
\hline Total & 100.00 & 100.00 & 100.00 & 100.00 & 100.00 & 100.00 & 100.00 \\
\hline
\end{tabular}

Fuente: DIGESTYC, Censos Económicos, 1992.

O sea, pues, que tan sólo 66 empresas catalogadas como grandes - de un total de 1,568 - controlan arriba del 50 por ciento de las remuneraciones pagadas y cerca de las tres cuartas partes de la producción bruta, lo cual claramente indica que la manufactura salvadoreña todavía está signada por la concentración. Aunque en términos de personas ocupadas las empresas medianas superan a las grandes, las medianas, que representan alrededor del 35 por ciento de las empresas, dan ocupación al 57.6 por ciento de los trabajadores del sector manulacturero de empresas con más de 4 trabajadores.

A lin de hacer un estudio lo más objetivo posible de la rcalidad, para evitar cualquier sesgo, en términos del critcrio de clasilicación de las empresás, se decidió emplear otro critcrio distinto del anterior; de esta manera se obluvieron los datos que se presentan en los Cuadros 3 y 4.
Otra forma de estudiar la concentración es mediante la clasificación de las empresas según el número de personas ocupadas en las mismas; así se consideran como pequeñas a aquellas empresas con más de 5 y menos de 20 personas ocupadas; medianas, a las que ocupan más de 20 y menos de 100 personas y, finalmente, se definió como grandes a las que emplean 100 o más personas. Una vez que se realizó el proceso de la información de acuerdo con tal criterio, se obluvieron los resultados que se presentan en el Cuadro 3.

Pese a la modificación del criterio, las empresas pequeñas son todavía la mayoría, en cambio las medianas se redujeron a 358 empresas $y$, obviamente, ya no ocupan más del 50 por ciento de las personas. Las empresas consideradas como grandes casi sc multiplican por tres, de 66 pasan a ser 183 . 


\section{Cuadro 3 \\ Estructura de las empresas de la industria manufacturera con más de 4 personas ocupadas, según el número de personas ocupadas por empresa, 1992}

\begin{tabular}{lccccccc}
\hline & \multicolumn{3}{c}{ Personal ocupado } & & \multicolumn{3}{c}{ Miles de colones } \\
\cline { 2 - 3 } $\begin{array}{l}\text { Personas } \\
\text { ocupadas }\end{array}$ & $\begin{array}{l}\text { Número } \\
\text { empresas }\end{array}$ & Total & Remunerado & & $\begin{array}{c}\text { Remunerac. } \\
\text { pagadas }\end{array}$ & \multicolumn{1}{c}{$\begin{array}{c}\text { Producción } \\
\text { bruta }\end{array}$} & \multicolumn{1}{c}{$\begin{array}{c}\text { Valor } \\
\text { agregado }\end{array}$} \\
\hline de 5 a 19 & 1,027 & 8,827 & 7,331 & 111,839 & 581,235 & 280,292 \\
de 20 a 99 & 358 & 16,175 & 15,592 & & 350,395 & $4,226,946$ & $1,251,150$ \\
de 100 y más & 183 & 55,233 & 54,970 & & $1,685,525$ & $14,446,668$ & $6,390,035$ \\
\hline Total & 1,568 & 80,235 & 77,893 & & $2,147,759$ & $19,254,849$ & $7,921,477$ \\
\hline
\end{tabular}

Fuente: DIGESTYC, Censos Económicos, 1992.

Al trasladar a porcentajes los valores absolutos del Cuadro 3, se obtuvieron los indicadores de concentración estadístico-estructural siguientes:

(a) Mientras que el 65.5 por ciento de las empresas del subsector apenas controlan el 9.4 por ciento del personal remunerado, el 5.2 por ciento de las remuneraciones pagadas, el 3.0 por ciento de la producción bruta y el 3.5 por ciento del valor agregado, en el extremo opuesto se tiene...

(b) que el 11.7 por ciento de las empresas conIrola el 70.6 por ciento del personal remunerado, y más de las tres cuartas partes de las remuneraciones pagadas y de la producción bruta y más de las cuatro quintas partes del valor agregado.
Esta es la realidad que refleja el Cuadro 4, y al observar las dos últimas columnas del mismo se verá que, en términos relativos, la producción bruta de las empresas medianas es inferior a su respectivo valor agregado; mientras que en las empresas grandes ocurre lo contrario: el valor agregado es mayor que la producción bruta, en términos porcentuales. Es decir, que porcentualmente a las empresas grandes les corresponde un mayor valor agregado que su respectiva producción bruta y que ese diferencial, ganado por las empresas grandes, se corresponde - en este caso- con el perdido por las empresas medianas. Esta situación se explica por las diferencias en cuanto a su productividad, como se verá más delante.

\section{Cuadro 4}

Estructura porcentual de las empresas de la industria manufacturera con más de 4 personas ocupadas, según el número de personas ocupadas 1992 (En porcentajes)

\begin{tabular}{|c|c|c|c|c|c|c|}
\hline \multirow[b]{2}{*}{$\begin{array}{l}\text { Personas } \\
\text { ocupadas }\end{array}$} & \multirow[b]{2}{*}{$\begin{array}{l}\text { Número } \\
\text { empresas (\%) }\end{array}$} & \multicolumn{2}{|c|}{ Personal ocupado } & \multicolumn{2}{|l|}{ 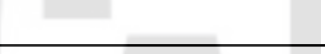 } & \multirow[b]{2}{*}{$\begin{array}{c}\text { Valor } \\
\text { agregado (\%) }\end{array}$} \\
\hline & & Total (\%) & $\begin{array}{c}\text { Remunerado } \\
(\%)\end{array}$ & $\begin{array}{l}\text { Remune. } \\
\text { pagadas (\%) }\end{array}$ & $\begin{array}{r}\text { Producción } \\
\text { bruta(\%) } \\
\end{array}$ & \\
\hline De 5 a 19 personas & 65.50 & 11.00 & 9.41 & 5.21 & 3.02 & 3.54 \\
\hline De 20 a 99 personas & 22.83 & 20.16 & 20.01 & 16.31 & 21.95 & 15.79 \\
\hline De 100 y más personas & 11.67 & 68.86 & 70.57 & 78.46 & 75.03 & 80.67 \\
\hline Total & 100.00 & 100.00 & 100.00 & 100.00 & 100.00 & 100.00 \\
\hline
\end{tabular}

Fuente: DIGESTYC, Censos Económicos, 1992. 
A fin de completar la información anterior, se presenta alguna información del subsector manufacturero y se desglosa en ramas industriales, de acuerdo con la CIIU (Clasificación Internacional Industrial Uniforme) a nivel de dos dígitos. A continuación se indica a qué ramas corresponden cada uno de los dígitos que se muestran en el cuadro que sigue.

$31=$ producción de alimentos bebidas y tabaco.

32 = lextiles, prendas de vestir e industria del cuero.

33 = industria de la madera.

34 = fábricas de papel, industrias de papel e imprentas.
35 = fabricación de sustancias y productos químicos derivados del petróleo.

36 = fabricación de productos minerales no metálicos.

37 = industrias metálicas básicas.

38 = fabricación de productos metálicos, maquinaria y equipo.

$39=$ otras industrias manufactureras

Estas son las 9 ramas en que se divide el sector industrial. En el Cuadro 5 se muestra cuál es la rama más importante en términos de ocupados, remuneraciones pagadas, producción bruta y valor agregado.

\section{Cuadro 5}

Estructura de las empresas de la industria manufacturera con más de 4 personas ocupadas, según las ramas de actividad económica, 1992

\begin{tabular}{|c|c|c|c|c|c|c|}
\hline \multirow[b]{2}{*}{ Ramas } & \multirow[b]{2}{*}{$\begin{array}{l}\text { No. } \\
\text { empresas }\end{array}$} & \multicolumn{2}{|c|}{ Personal ocupado } & \multicolumn{2}{|c|}{ Miles de colones } & \multirow[b]{2}{*}{ Valor } \\
\hline & & $\begin{array}{l}\text { Total } \\
\text { pagadas }\end{array}$ & $\begin{array}{l}\text { Remunerado } \\
\text { bruta }\end{array}$ & $\begin{array}{l}\text { Remun. } \\
\text { agregado }\end{array}$ & Producción & \\
\hline 31 & 362 & 16,180 & 15,544 & 513,749 & $4,783,709$ & $2,296,265$ \\
\hline 32 & 325 & 29,976 & 29,531 & 579,261 & $2,515,937$ & $1,310,224$ \\
\hline 33 & 139 & 1,708 & 1,520 & 26,843 & 142,448 & 71,945 \\
\hline 34 & 161 & 5,847 & 5,627 & 181,695 & $1,214,607$ & 584,801 \\
\hline 35 & 160 & 12,074 & 11,830 & 394,458 & $4,912,308$ & $1,517,129$ \\
\hline 36 & 170 & 4,049 & 3,815 & 91,341 & 857,642 & 485,278 \\
\hline 37 & 12 & 1,674 & 1,657 & 36,443 & 307,822 & 102,274 \\
\hline 38 & 201 & 7,326 & 7,030 & 299,607 & $4,387,169$ & $1,481,040$ \\
\hline 39 & 38 & 1,401 & 1,339 & 24,362 & 133,207 & 72,521 \\
\hline Total & 1.568 & 80,235 & 77,893 & $2,147,759$ & $19,254,849$ & $7,921,477$ \\
\hline
\end{tabular}

Fuente: DIGESTYC, Censos Económicos, 1992.

Básicamente, el número de empresas y el de personas ocupadas y remuneradas se concentran en dos ramas: la 31 y la 32 . Sin embargo, en lo que se refiere a producción bruta y valor agregado, la rama 32 pierde importancia y se destacan la 31 , la 35 y la 38 .

Como se observa en el Cuadro 6, en la rama 31 se encuentra el 23.1 por ciento de las empresas, lo cual representa el mayor número de empresas; mismas que controlan el mayor volumen de valor agregado, esto es, el 29 por ciento. Mientras que el mayor volumen de personal ocupado y remunerado, así como las remuneraciones pagadas se concentran en la rama 32 , que corresponden al 37.4 , 37.9 y 27.0 por ciento, respectivamente.

En cambio, cuando se trata de la producción bruta, el mayor volumen se concentra en la rama 35 , la cual controla 25.5 por ciento de la misma; aunque las empresas correspondientes a esta rama representan apenas el 10.2 por ciento de las mismas, el 15 por ciento de las personas ocupadas y el 18.4 por ciento de las remuneraciones pagadas. 
Esto obedece a que en la rama 35 se ubica la refinería de petróleo, la cual insume gran cantidad de materia prima y esto se traduce en un elevado valor bruto de la producción.

\section{Cuadro 6}

Estructura porcentual de las empresas manufactureras con más de 4 personas ocupadas, por rama de actividad económica, 1992

\begin{tabular}{lcccccc}
\hline Ramas & $\begin{array}{c}\text { No. } \\
\text { empresas (\%) }\end{array}$ & $\begin{array}{c}\text { Personal } \\
\text { total }(\%)\end{array}$ & $\begin{array}{c}\text { Personal } \\
\text { remunerado (\%) }\end{array}$ & $\begin{array}{l}\text { Remuner. } \\
\text { pagadas (\%) }\end{array}$ & $\begin{array}{c}\text { Producción } \\
\text { bruta (\%) }\end{array}$ & $\begin{array}{c}\text { Valor } \\
\text { agregado (\%) }\end{array}$ \\
\hline 31 & 23.09 & 20.17 & 19.96 & 23.92 & 24.84 & 28.99 \\
32 & 20.73 & 37.36 & 37.91 & 26.97 & 13.07 & 16.54 \\
33 & 8.86 & 2.13 & 1.95 & 1.25 & 0.74 & 0.91 \\
34 & 10.27 & 7.29 & 7.22 & 8.46 & 6.31 & 7.38 \\
35 & 10.20 & 15.05 & 15.19 & 18.37 & 25.51 & 19.15 \\
36 & 10.84 & 5.05 & 4.90 & 4.25 & 4.45 & 6.13 \\
37 & 0.76 & 2.09 & 2.13 & 1.70 & 4.45 & 1.29 \\
38 & 12.82 & 9.13 & 9.03 & 13.95 & 22.78 & 18.70 \\
39 & 2.42 & 1.75 & 1.72 & 1.13 & 0.69 & 0.92 \\
\hline \multirow{2}{*}{ Total } & 100.00 & 100.00 & 100.00 & 100.00 & 100.00 & 100.00 \\
\hline
\end{tabular}

Fuente: DIGESTYC, Censos Económicos, 1992.

De las 9 ramas industriales, en la rama 32 se concentra la mayor cantidad de personas ocupadas y remuneradas porque en ella predominan las técnicas intensivas en mano de obra, como son las actividades textiles y de la confección de vestuario. Ello tambićn se refleja en el hecho de que, en términos relativos, el valor agregado representa un mayor valor que la producción bruta.
2.1.1. Relación entre los salarios y la productividad, según el tamaño de las empresas

Independientemente de que los salarios, en general, son bastante bajos, es bastante lamentable que sean más bajos cuanto más pequeñas son las empresas, lo cual se traduce en que los salarios promedios de las pequeñas y medianas empresas estén por debajo de la media nacional.

\section{Cuadro 7}

Salarios anuales y productividad media por tamaño de las empresas, según el valor bruto de la producción, 1992

\begin{tabular}{lcc}
\hline Valor bruto producción & Salarios promedio & Productividad media \\
\hline Empresa pequeña & $12,807.82$ & $20,161.08$ \\
Empresa mediana & $20,863.43$ & $51,367.45$ \\
Empresa grande & $42,952.59$ & 206.065 .84 \\
Promedio sector & $27,573.19$ & $98,728.44$ \\
\hline
\end{tabular}

Fuente: DIGESTYC, Censos Económicos, 1992. 
Antes de proseguir se aclarará la forma en que se ha obtenido la productividad, ya que su misma estimación está determinando una mayor cuantía en las grandes empresas, aunque ello no resulte algo irracional o imposible. La productividad resulta de dividir el valor agregado censal entre el número de ocupados, lo que significa que del valor agregado no se ha disminuido la depreciación de los activos fijos, mismos que son cuantitativamente más significativos en las empresas grandes que en las pequeñas y medianas.

La misma metodología se ha empleado en los Cuadros 7 y 8 . Los resultados son bastante semejantes cuando se clasifica a las empresas desde el punto de vista del valor bruto de la producción - Cuadro 7- que cuando se hace según el número de personas ocupadas, como se muestra en la información del Cuadro 8.

Resulta interesante mostrar que a mayores salarios mayor productividad, y que al comparar el salario de las empresas pequeñas con el de las grandes se liene que, si bien el salario promedio en las empresas grandes duplica al de las pequeñas, la productividad en las empresas grandes cuadruplica a la respectiva productividad de las empresas pequeñas, lo cual debería de ser un aliciente para incrementar los salarios a los trabajadores.

\section{Cuadro 8}

Salarios anuales y productividad media por tamaño de las empresas, según el numero de personas ocupadas, 1992

\begin{tabular}{lcc}
\hline Personas ocupadas & Salarios promedio & Productividad media \\
\hline Empresa pequeña & $15,255.62$ & $31,753.93$ \\
Empresa mediana & $22,472.74$ & $77,350.85$ \\
Empresa grande & $30,662.63$ & $115,692.33$ \\
\hline Promedio sector & $27,573.19$ & $98,728.44$ \\
\hline
\end{tabular}

Fuente: DIGESTYC, Censos Económicos, 1992.

\subsection{La concentración por rama económica en las microempresas}

Es bastante evidente que la mayoría de microempresas se concentran en dos ramas de la industria manufacturera: la 31 y la 32 , las cuales concentran el 59 por ciento de los ocupados, el 49 por ciento de los remunerados, el 46.3 por ciento de las remuneraciones pagadas y un poco más de la mitad de la producción bruta y el valor agregado. O sea, pues, que la microproducción se con- centra en actividades como los alimentos, las bebidas, los textiles y las confecciones de vestuario. Sin embargo, son ramas en las cuales la productividad está por debajo de la productividad media del sector, seguramente porque son actividades bastante intensivas en el uso de mano de obra.

El promedio de ocupados por microempresa casi asciende a dos personas, lo que equivale al 1.97. No obstante, el número de remunerados no alcanza ni siquiera a una persona por establecimiento, lo que establece una relación de 0.75 . 


\section{Cuadro 9}

Manufactura con 4 y menos personas ocupadas, por rama de actividad económica, 1992.

\begin{tabular}{lrrrrrrr}
\hline Manufacturas & $\begin{array}{l}\text { No. de } \\
\text { estable. }\end{array}$ & $\begin{array}{l}\text { Total } \\
\text { ocupados }\end{array}$ & Remunerados & $\begin{array}{l}\text { Remun. } \\
\text { pagadas }\end{array}$ & \multicolumn{1}{l}{$\begin{array}{l}\text { Producción } \\
\text { bruta }\end{array}$} & $\begin{array}{l}\text { Valor } \\
\text { agregado }\end{array}$ & Productividad \\
\hline $\begin{array}{l}\text { Total } \\
\text { Ramas }\end{array}$ & 6,314 & 12,443 & 4,707 & 47,741 & 349,789 & 179,789 & 14,449 \\
31 & 1,896 & 3,581 & 1,151 & 11,531 & 106,845 & 47,575 & 13,285 \\
32 & 2,253 & 3,765 & 1,157 & 10,569 & 70,420 & 43,495 & 11,552 \\
33 & 843 & 1,848 & 798 & 8,076 & 55,958 & 28,978 & 15,680 \\
34 & 125 & 354 & 208 & 2,587 & 12,936 & 7,926 & 22,389 \\
35 & 35 & 98 & 53 & 720 & 8,834 & 4,604 & 46,979 \\
36 & 339 & 883 & 468 & 4,717 & 27,418 & 14,432 & 16,344 \\
37 & 1 & 2 & 1 & 11 & 40 & 27 & 13,500 \\
38 & 744 & 1,753 & 818 & 8,927 & 62,086 & 29,549 & 16,856 \\
39 & 78 & 159 & 53 & 603 & 4,942 & 3,203 & 10,025 \\
\hline
\end{tabular}

Fuente: DIGESTYC, Censos Económicos, 1992.

La productividad media es bastante baja y es superada por la productividad media de las empresas pequeñas. Aunque de manera excepcional, la productividad microempresarial —en la rama 35 - supera la productividad promedio de las empresas pequeñas.

\subsection{Visión global de la concentración en la in- dustria manufacturera}

En cl Cuadro 10 se presenta un resumen de toda la información anterior, la cual se mostró de manera desglosada; a partir de ella es posible observar la grave heterogencidad estructural que presenta el sector industrial salvadoreño, en donde la gran mayoría de establecimientos son microempresas. Antes de proseguir se harán algunas observaciones al respecto.

La produclividad media estimada presentaba las magnitudes siguientes:

Microempresa

Empresa pequeña.
Empresa mediana

51,367

Empresa grande

206,065

$\mathrm{Si}$ además se considera que la gran empresa industrial tan sólo ocupa el 28.3 por ciento de las personas ocupadas en el sector, en el supuesto de que sus niveles de productividad sean aceptables, se puede sostener que más del 70 por ciento de la población trabajadora en el sector industrial está subutilizada.

Esta problemática de la heterogeneidad estructural, tan destacada en la década de los setenta por los estructuralistas, ha pasado al olvido como otros tantos males de la realidad latinoamericana $y$, en particular, de nuestro país, como si existiese la creencia de que los males, para que desaparezcan, basta con no mencionarlos. Pero bien, ahora que tanto se habla de globalización, apertura comercial y competitividad es importante percatarse de quiénes tienen que ver con toda esta problemática, de cuáles son los niveles de productividad con los que se piensa enfrentar a las importaciones de manufacturas y, por otra parte, incursionar en los mercados extranjeros. 


\section{Cuadro 10}

Estructura de la producciön manufacturera salvadoreña:

micro, pequeña, mediana y gran empresa, según el VBP, 1992

\begin{tabular}{lrrrrrr}
\hline & \multicolumn{5}{c}{ Ocupados } & Valor en miles de colones \\
\cline { 2 - 7 } $\begin{array}{l}\text { Valor Bruto } \\
\text { Producción }\end{array}$ & $\begin{array}{c}\text { No. de } \\
\text { empresas }\end{array}$ & Total & Remunerados & \multicolumn{1}{l}{$\begin{array}{l}\text { Remunera. } \\
\text { pagadas }\end{array}$} & \multicolumn{1}{c}{$\begin{array}{l}\text { Prod. } \\
\text { bruta }\end{array}$} & \multicolumn{1}{c}{$\begin{array}{l}\text { Valor } \\
\text { agregado }\end{array}$} \\
\hline Micro & 6,314 & 12,443 & 4,707 & 47,741 & 349,479 & 179,787 \\
Pequeñas & 946 & 8,244 & 6,848 & 87,708 & 325,941 & 166,208 \\
Medianas & 556 & 45,764 & 44,887 & 936,497 & $4,830,931$ & $2,350,780$ \\
Grandes & 66 & 26,227 & 26,158 & $1,123,554$ & $14,097,977$ & $5,404,489$ \\
Total & 7,882 & 92,678 & 82,600 & $2,195,500$ & $19,604,328$ & $8,101,264$ \\
\hline
\end{tabular}

Fuente: DIGESTYC, Censos Económicos, 1992.

Conocerlo, ciertamente, no cambia en mucho la realidad; sin embargo, ayuda a desvanecer muchos sueños o "viajes mariguanescos" como es más del agrado decir a nuestra sociedad postmoderna anclada en una terrible y profunda heterogeneidad estructural, de la cual se hubiera escandalizado, inclusive, Anibal Pinto, uno de sus principales analistas.

También es preciso señalar que si bien la heterogeneidad estructural ha sido muy funcional al modelo económico vigente hasta hace algunas décadas, en la actualidad ya no es compatible con la apertura comercial y la globalización de la economía. No percatarse de ello y no actuar en conse- cuencia, tendrá serias repercusiones económicas, sociales y políticas.

Pero bien, luego de este largo paréntesis, ahora se analizará el objetivo principal de esta investigación: la concentración. Lo primero que llama la atención en el Cuadro 10 es el número total de empresas: 7,882. De ese total, 6,314 son microempresas, las cuales controlan un número mayor de ocupados que las empresas pequeñas y generan, a su vez, una mayor producción bruta y un mayor valor agregado que las mismas, aunque el número de microempresas es 6 veces mayor que el número de empresas pequeñas. No obstante los datos anteriores, las empresas pequeñas pagan casi el doble de remuneraciones que las microempresas.

\section{Cuadro 11}

Estructura porcentual de la producción

manufacturera salvadoreña: micro, pequeña, mediana y gran empresa, según el VBP, 1992

\begin{tabular}{llllllll}
\hline & & \multicolumn{2}{c}{ Ocupados } & & \multicolumn{3}{c}{ Valor en miles de colones } \\
$\begin{array}{l}\text { Valor Bruto } \\
\text { Producción }\end{array}$ & $\begin{array}{l}\text { No. de } \\
\text { Empresas (\%) }\end{array}$ & Total (\%) & $\begin{array}{l}\text { Remunerados } \\
(\%)\end{array}$ & & $\begin{array}{l}\text { Remunerac. } \\
\text { pagadas (\%) }\end{array}$ & $\begin{array}{c}\text { Prod. } \\
\text { Bruta (\%) }\end{array}$ & $\begin{array}{c}\text { Valor } \\
\text { agregado (\%) }\end{array}$ \\
\hline Micro & 80.1 & 13.4 & 5.7 & & 2.2 & 1.8 & 2.2 \\
Pequeñas & 12.0 & 8.9 & 8.3 & & 4.0 & 1.7 & 2.1 \\
Medianas & 7.0 & 49.3 & 54.3 & & 42.7 & 24.6 & 29.0 \\
Grandes & 0.8 & 28.3 & 31.7 & & 51.2 & 71.9 & 66.7 \\
\hline Total & 100.0 & 100.0 & 100.0 & & 100.0 & 100.0 & 100.0 \\
\hline
\end{tabular}

Fuente: DIGESTYC, Censos Económicos, 1992. 
Ahora bien, la magnitud de la concentración se observa con claridad en la información del Cuadro 11 , en donde al 80.1 por ciento de las empresas corresponde solamente el 2.2 por ciento de las remuneraciones pagadas, el 1.8 por ciento de la producción bruta y el 2.2 por ciento del valor agregado; mientras en el otro extremo, al 0.8 por ciento de las empresas corresponde el 51.2 por ciento de las remuneraciones, el 71.9 por ciento de la producción bruta y el 66.7 por ciento del valor agregado.

Dicho en otras palabras, dos tercios de la riqueza generada en el sector industrial manufacturero se concentra en el 0.8 por ciento de las empresas; éste es el fenómeno de la concentración estadístico-estructural, la cual tiene a la base dos tendencias claves del capitalismo: la concentración idéntica a la acumulación y la centralización del capital.

Por otra parte, es bueno destacar que las empresas medianas, que constituyen el 7 por ciento de las empresas, ocupan a casi la mitad de las personas del sector, esto es, al 49.3 por ciento; contratan a más de la mitad, es decir, al 54.3 por ciento de los remunerados; pagan casi la mitad de las remuneraciones, que equivalen al 42.7 por ciento, aunque sólo controlan el 24.6 por ciento de la producción bruta y el 29 por ciento del valor agregado.

Ahora bien, si se suman ambos tipos de empresas - medianas y grandes- se tendría que el 7.8 por cicnto de las empresas controlan: 77.6 por ciento de los ocupados; 86 por ciento de los remunerados; 93.9 por ciento de las remuneraciones; 96.5 por ciento de la producción bruta y 95.7 por ciento del valor agregado, lo cual es una forma de indicar que el sector capitalista controla la producción industrial manufacturera en El Salvador.

\section{Consideraciones finales}

Si sostenemos que la concentración y la centralización del capital se presentan como tendencias normales en el capitalismo y que ambas se manifiestan en la concentración estadístico-estructural, la cual también es, en consecuencia, resultado normal del capitalismo, cabe preguntarse: ¿cuál es entonces el problema? Seguramente el problema no tenga que ver con la concentración estadístico-estructural en sí misma, ya que ésta es el resultado del crecimiento de las empresas, lo cual significa que la economía se engrandece y ello no puede, en ningún momento, considerarse como algo problemático, sino que todo lo contrario.

El problema, entonces, habría que buscarlo en otro lugar, como por ejemplo, en las consecuencias del gran crecimiento de las empresas que puede derivar o traducirse en monopolios u oligopolios, con todas las implicaciones negativas que se derivan de su existencia en una determinada economía. También es preciso dejar claro de que tal concentración implica concentración de la propiedad y, como consecuencia directa de la misma, concentración del ingreso. Esta no sólo presenta problemas en términos del mercado - ya que la demanda real se reduce significativamente $y$, por ende, se limita el crecimiento económico-, sino que tiene serias consecuencias en términos sociales y de equidad puesto que es un factor muy importante en la determinación de la pobreza.

En cuanto a la concentración de los ingresos, se cita la información presentada por María Dolores Albiac en su trabajo: "Los ricos más ricos de El Salvador", publicado recientemente por Ediciones Heinrich Böll:

a) Los pobres, con ingresos inferiores a 3,000 colones (350 dólares), aún constituyen el 62 por ciento de la población, $754 \mathrm{mil}$ hogares (aproximadamente 3.7 millones de personas).

b) La clase media, con ingresos entre 3,000 y 14,300 colones ( 350 a 1,640 dólares), suman el 31 por ciento de la población...

c) La clase alta, con ingresos desde 15 hasta 71 mil (1,725 a 8 mil dólares), es de sólo el 1 por ciento de la población....

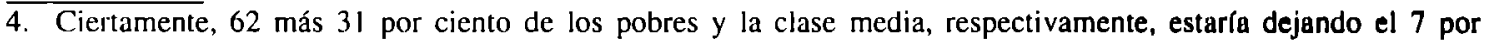
ciento para el otro estrato y no el 1 como lo presenta la autora. 
La pobreza en El Salvador, según el Informe sobre Desarrollo Humano del PNUD para 1997. presentaba los indicadores siguientes:

- Se estima que el 11.7 por ciento de la población no alcanzará los 40 años de vida.

- El 60 por ciento de la población no tiene acceso a servicios de salud.

- El 31 por ciento de la población no tiene acceso a agua potable.

- El Indice de Pobreza Humana en el país es del 28.0 por ciento, mientras que en Costa Rica es del 6.6 por ciento.

Ahora bien, es importante considerar que aunque la concentración de la propiedad incide en la concentración del ingreso y ésta se manifiesta en situaciones de pobreza, no se cumple que - dentro del sistema- al redistribuir la propiedad se mejo-

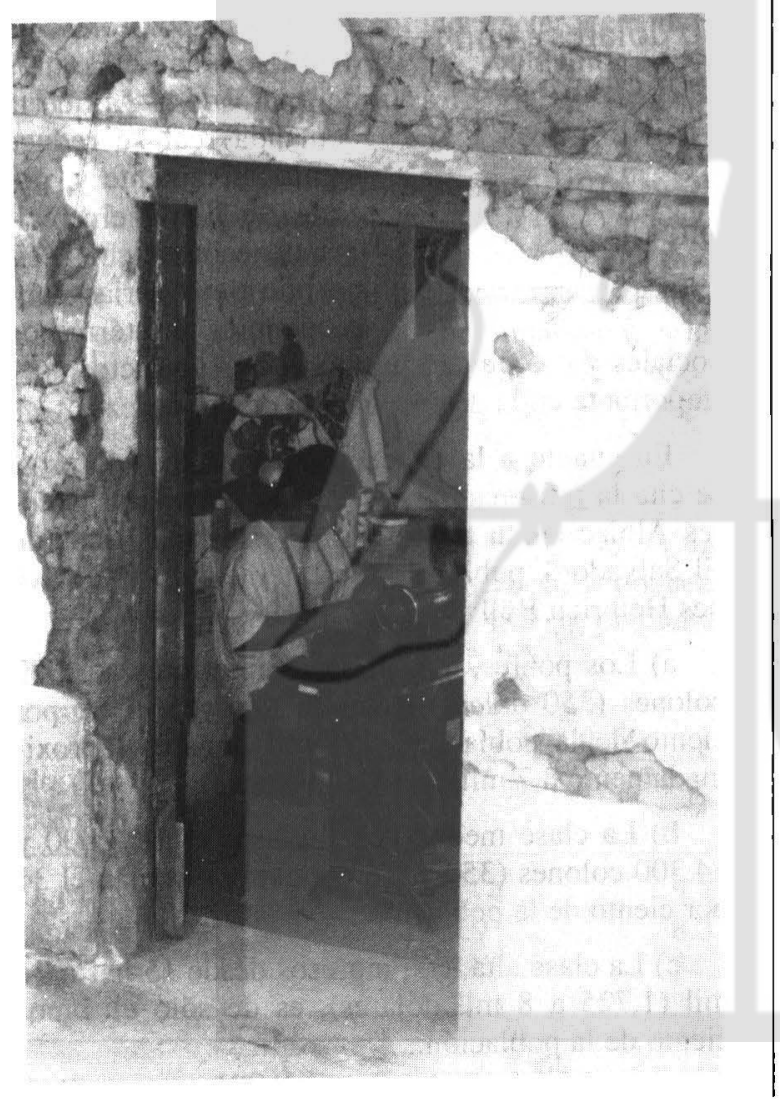

re la distribución del ingreso y se elimine la pobreza. Esta situación es mucho más compleja de lo que parece y no admite una simple relación mecánica de causa y efecto, puesto que la simple redistribución de la propiedad puede traducirse en una mera generalización de la pobreza, y no en una mejora del ingreso como pudiera pensarse.

Sin embargo es posible abatir la pobreza con la elevación de los salarios y la generación de empleo y, por medio de éste, mejorar la distribución del ingreso, ya sea vía salarios, o bien, mediante ingresos personales directos. .

Para que esta última opción sea posible es preciso contribuir a que los pobres tengan acceso a algún tipo de activos materiales e inmateriales. Entre los activos materiales cabe mencionar los recursos productivos, como tierra, maquinaria, equipo, etc.; y entre los inmateriales, la formación técnica, ya sea en materia de producción, gestión empresarial, comercialización, etc. Todo ello indica que esta manera de enfrentar la pobreza es un proceso largo, compendioso y que exige de muchos recursos, así como de mucha claridad en cuanto al proceso que se busca impulsar.

Aunque siempre existe la esperanza y la posibilidad real de combatir la pobreza vía la generación de empleo asalariado, mediante la maquila, o de una determinada reacción económica que se traduzca en crecimiento económico y en demanda de nuevos trabajadores; el combate a la pobreza, en ambos casos, no se presenta como un objetivo directo, sino que puede ocurrir si los empresarios capitalistas encuentran estímulos y expectativas de buenas ganancias que los animen a invertir.

El carácter azaroso de esta situación se observa en el hecho de que existe pobreza, pese a que existen muchas personas que desean trabajar y obtener ingresos que les posibiliten salir de la miseria; y las inversiones no se dan por la sencilla razón de que éstas no están en función de la existencia o no de personas desempleadas o subempleadas.

Si bien los empresarios generan puestos de trabajo, lo que buscan no es ocupar personas sino obtener ganancias, de allí que si pueden obtenerlas con el mínimo de empleados, pucs, mejor. Por tal motivo se prefiere a las máquinas, aunque quienes necesiten del empleo sean los obreros. 
Anexo 1

Clasificación de Bancos y financieras

\begin{tabular}{lcc}
\hline & Activos (\%) & Depósitos (\%) \\
\hline Agrícola & 20.80 & 22.50 \\
Cuscatlán & 20.00 & 18.10 \\
Salvadoreño & 12.50 & 12.26 \\
Comercio & 8.16 & 8.42 \\
Desarrollo & 6.80 & 6.90 \\
Bancasa & 5.45 & 5.47 \\
Credisa & 5.31 & 5.95 \\
Ahorromet & 4.96 & 4.60 \\
Atlacall & 2.56 & 2.92 \\
Multivalores & 1.75 & 1.98 \\
Unibanco & 1.48 & 1.13 \\
Bancorp & 1.38 & 1.22 \\
Finsepro & 1.10 & 1.20 \\
Ficsa & 1.08 & 1.23 \\
Capital & 0.91 & 0.58 \\
Promerica & 0.50 & 0.49 \\
Fincomer & 0.35 & 0.37 \\
Calpia & 0.22 & 0.01 \\
\hline Total & 100.00 & 100.00 \\
\hline
\end{tabular}

Fuente: Elaborado por Paniagua, C. R., et al, a partir de información de la Superintendencia de Valores, Revista Bursátil, octubre-diciembre, 1996. 